\title{
Adultos com Síndrome de Down
}

Natalia Neves MACEDO ${ }^{1}$

Gabriela Ruiz BERRIBILLE²

CARNEIRO, Maria Sylvia Cardoso. A dultos com Síndrome de D own. A deficiência mental como produção social. Campinas, SP: Papirus, 2008 (Série Educação Especial).

O livro intitulado "Adultos com Síndrome de Down - A deficiência mental como produção social", da série Educação Especial, Iançado pela editora Papirus no ano de 2008, destina-se a leitores e pesquisadores que se interessam e vêem-se envolvidos em estudos sobreSíndrome de Down e Deficiência Intelectual e a compreensão desta deficiência como uma condição socialmente construída, resultado deum entrelaçamento indivisível entreos aspectos biológicos eculturais.

Este livro é derivado de uma pesquisa desenvolvida por Maria Sylvia Cardoso Carneiro no período de 2003 a 2006, durante seu doutorado no Programa dePós-Graduação em Educação daUFRGS. O principal objetivo da obra é discutir a deficiência mental como uma condição que se desenvolve a partir das relações sociais estabelecidas com sujeitos queapresentam al gum tipo de comprometimento orgânico. Para tanto, são focal izadas as particularidades esi milaridades presentes nas histórias de três adultos com Síndrome de Down, os quais, devido às oportunidades que tiveram desde a infância, percorreram trajetórias de desenvolvimento bastante distintas das tradicional menteesperadas pela sociedade para pessoas com essa deficiência. A partir da descrição e discussão dessas histórias, procura-se focal izar e analisar a ruptura com os prognósticos negativos, a construção de outras possi bilidades de desenvolvimento ea imagem queo sujeito com nesta condição faz de si mesmo. A pesar de estar presente nos três sujeitos da pesquisa, o livro não discute a Síndrome de Down, mas sim a idéia de que a constituição de sujeitos na condição de deficientes mentais está vinculada, sobretudo, às relações sociais estabelecidas com eles.

O livro está dividido em cinco capítulos. No primeiro, intitulado "Deficiência Mental", é apresentado um levantamento histórico sobre o estudo da deficiência mental, seu conceito, definição e classificação, desde as

\footnotetext{
${ }_{1}^{1}$ Mestranda do Programa de Pós-Graduação em Educação Especial da Universidade Federal de São Carlos - Bolsista CNPq - natanema@gmail.com.

${ }^{2}$ Licencianda do curso de Educação Especial da Universidade Federal de São Carlos - Bolsista CN Pq/ IC - gabi_sbb@hotmail.com.
} 
contribuições de Jean Itard e Sèguin até o discurso da American Association on Mental Retardation (AAMR), no Sistema 2002, no qual trás uma visão multidimensional da deficiência.

No capítulo dois, denominado "A abordagem histórico-cultural e os estudos de defectologia", a autora, apoiada na abordagem histórico-cultural e nas contribuições de Vygotsky, discute as influências e interferências do meio no desenvol vimento pessoal, social ecultural do sujeito, apresentando conceitos como o de Nível de Desenvolvimento Efetivo e Zona de Desenvolvimento Proximal, desenvolvidos por Vygotsky e que nos ajudam a compreender a interconexão entre o ensino e o desenvolvimento. Com base na relação indissociável entre os aspectos biológicos e culturais, a autora defende seu argumento de que a deficiência mental é uma produção social, construída na medida em que não se possibilitam formas de desenvolvimento compatíveis com as necessidades dos sujeitos nesta condição.

O terceiro capítulo, denominado “A s histórias de vida como estratégia metodológica" traz a justificativa e uma importante reflexão sobre o método adotado para a realização da pesquisa, qual seja, História de Vida, apontando a importância de métodos narrativos em pesquisas que estudam pessoas consideradas deficientes mentais. A lém disso, são apresentados os procedimentos metodológicos utilizados para a pesquisa, como a escolha da amostra, o perfil dos sujeitos entrevistados, o contato com eles e a forma como as histórias foram sendo elaboradas ao longo do estudo.

O capítulo quatro, “As histórias de Ivan, Paula e León”, apresenta brevemente algumas informações e reflexões sobre al gumas particularidades que em geral estão presentes em pessoas com Síndrome de Down. Em seguida, são apresentadas de forma clara e fiel as três histórias relatadas pelos sujeitos da pesquisa. Nestas histórias são narrados o desenvolvimento, as dificuldades e as superações pessoais, familiares, acadêmicas e profissionais de Ivan, Paula e Léon.

No quinto e último capítulo, intitulado "A Igumas reflexões a partir das histórias", a autora traz algumas considerações acerca das similaridades e peculiaridades das três histórias narradas, identificando importantes elementos constitutivos dos sujeitos, como a escolarização no ensino comum, a imagem que cada um tem de si mesmo e as vivências no mundo do trabalho. Ao refletir sobre as narrativas, Carneiro mostra-nos que as dificuldades enfrentadas por pessoas com deficiência mental, para além da condição orgânica, estão relacionadas com as interações vividas por estas pessoas nos diferentes contextos sociais.

Trata-se, portanto, de uma obra de grande relevância social e acadêmica, que mostra experiências de vida positivas de pessoas que, mesmo apresentando dificuldades significativas, romperam com as expectativas negativas da sociedade e construíram novas possibilidades, constituindo-se agentes de sua própria história. 